\title{
Artificial CSF Motion Ensures Rhythmic Activity in the Developing CNS Ex Vivo: A Mechanical Source of Rhythmogenesis?
}

\author{
Blaise Yvert, ${ }^{1}$ Claire Mazzocco, ${ }^{1}$ Sébastien Joucla, ${ }^{1}$ Adeline Langla, ${ }^{1}$ and Pierre Meyrand ${ }^{2}$ \\ ${ }^{1}$ Institut des Neurosciences Cognitives et Intégratives d'Aquitaine, CNRS, Université de Bordeaux, UMR5287, Talence, F-33405 France, and ${ }^{2}$ Institut des \\ Maladies Neurodégénératives, CNRS, Université de Bordeaux, UMR5293, Bordeaux, F-33000 France
}

\begin{abstract}
Spontaneous rhythmic activity is a ubiquitous feature of developing neural structures that has been shown to be essential for the establishment of functional CNS connectivity. However, the primordial origin of these rhythms remains unknown. Here, we describe two types of rhythmic activity in distinct parts of the developing CNS isolated ex vivo on microelectrode arrays, the expression of which was found to be strictly dependent upon the movement of the artificial CSF (aCSF) flowing over the inner wall of the ventricles or over the outer surface of the CNS. First, whole embryonic mouse hindbrain-spinal cord preparations (stages E12.5-E15.5) rhythmically expressed waves of activity originating in the hindbrain and propagating in the spinal cord. Interestingly enough, the frequency of this rhythm was completely determined by the speed of the aCSF flow. In particular, at all stages considered, hindbrain activity was abolished when the perfusion was stopped. Immature rhythmic activity was also recorded in the isolated newborn (P0 - P8) mouse cortex under normal aCSF perfusion. Again, this rhythm was abolished when the perfusion flow was stopped. In both structures, this phenomenon was not due to changes in temperature, oxygen level, or $\mathrm{pH}$ of the bath, but to the movement itself of the aCSF. These observations challenge the so-called "spontaneous" nature of rhythmic activity in immature neural networks and suggest that the movement of CSF in the ventricles and around the brain in vivo may mechanically drive rhythmogenesis in the developing CNS.
\end{abstract}

\section{Introduction}

Endogenous rhythmic activity is a key feature of immature neural networks that has been described in many developing structures of the CNS, including the retina, cochlea, spinal cord, hindbrain, cerebellum, thalamus, hippocampus, and cortex (Galli and Maffei, 1988; Ben-Ari et al., 1989; Yuste et al., 1992; O’Donovan, 1999; Garaschuk et al., 2000; Ben-Ari, 2002; Leinekugel et al., 2002; Yvert et al., 2004; Hunt et al., 2005; Dupont et al., 2006; Spitzer, 2006; Momose-Sato et al., 2007; Allène et al., 2008; Blankenship and Feller, 2010), and shown to be essential for the establishment of functional network connectivity (Penn et al., 1998; Hanson and Landmesser, 2004; Cang et al., 2005). Although previous studies have been devoted to deciphering the cellular and synaptic mechanisms underlying such activity $(\mathrm{Ta}-$

Received March 17, 2011; revised April 22, 2011; accepted April 28, 2011.

Author contributions: B.Y. and C.M. designed research; B.Y., C.M., and A.L. performed research; B.Y. and S.J. contributed unpublished reagents/analytic tools; B.Y., C.M., and A.L. analyzed data; B.Y., C.M., and P.M. wrote the paper.

This work was supported in part by grants to B.Y. from the French Ministry for Research and Technology (ACI, RMNT), the French National Research Agency (ANR—Programme Blanc ANR06BLAN035601 and ANR07BLAN028803), the Fyssen Foundation, Fondation pour la Recherche Médicale, and the Région Aquitaine (Grants 20030301201A and 20040301202A). We also thank P. Branchereau, D. Cattaert, X. Leinekugel, and J.-L. Morel for fruitful discussions, P. Chauvet for technical support, J. Swendsen for careful reading of an earlier version of the manuscript, and G. Bouchard ("Or et Façon") for skillful work.

Correspondence should be addressed to Dr. Blaise Yvert, CNRS and Université de Bordeaux, Institut des Neurosciences Cognitives et Intégratives d'Aquitaine, UMR 5287, Bâtiment B2, Avenue des facultés, 33405 Talence cedex, France. E-mail. blaise.yvert@u-bordeaux1.fr.

DOI:10.1523/JNEUROSCI.1354-11.2011

Copyright $\odot 2011$ the authors $\quad 0270-6474 / 11 / 318832-09 \$ 15.00 / 0$ bak et al., 2000; Ben-Ari, 2002), the primal mechanism responsible for the generation of immature rhythms remains largely unknown. Recent work has reported that sensory information, such as spontaneous body movements or retinal bursts, triggers episodes of immature cortical activity during development (Khazipov et al., 2004; Hanganu et al., 2006). However, this activity remains present when sensory inputs are absent, suggesting that other unknown fundamental mechanisms remain to be uncovered. To address this question, we focused on two distinct structures of the mouse CNS expressing immature rhythmic activity at different developmental times, namely the embryonic hindbrain-spinal cord and the postnatal cortex. Indeed, immature rhythmic activity in the former structures is largely expressed at embryonic stages (Provine et al., 1970; O'Donovan, 1989; Nishimaru et al., 1996; Hanson and Landmesser, 2003; Yvert et al., 2004; Hunt et al., 2005; Thoby-Brisson et al., 2005; MomoseSato et al., 2007), while cortical networks express major rhythms during the first postnatal week (Yuste et al., 1992; Khazipov et al., 2004; Allène et al., 2008). In both cases, we found that the emergence of activity was strictly dependent upon the movement of artificial CSF (aCSF) around the tissue.

\section{Materials and Methods}

Preparations. The present study relies on the overall use of $n=39$ mouse embryos (for hindbrain-spinal cord preparations) and $n=23$ newborn mouse pups (for cortical preparations). Pregnant OF1 mice (Charles River Laboratories) were killed by cervical dislocation, and embryos were removed and decapitated above the pons before the whole hindbrain- 


\section{a Hindbrain}

a1.

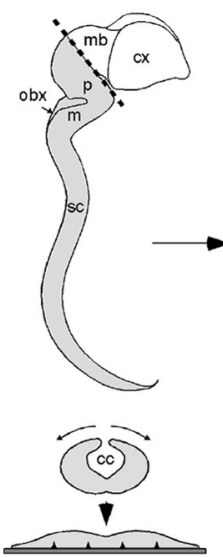

a2.

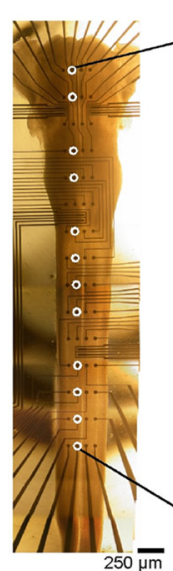

a3.

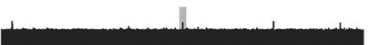

a4.

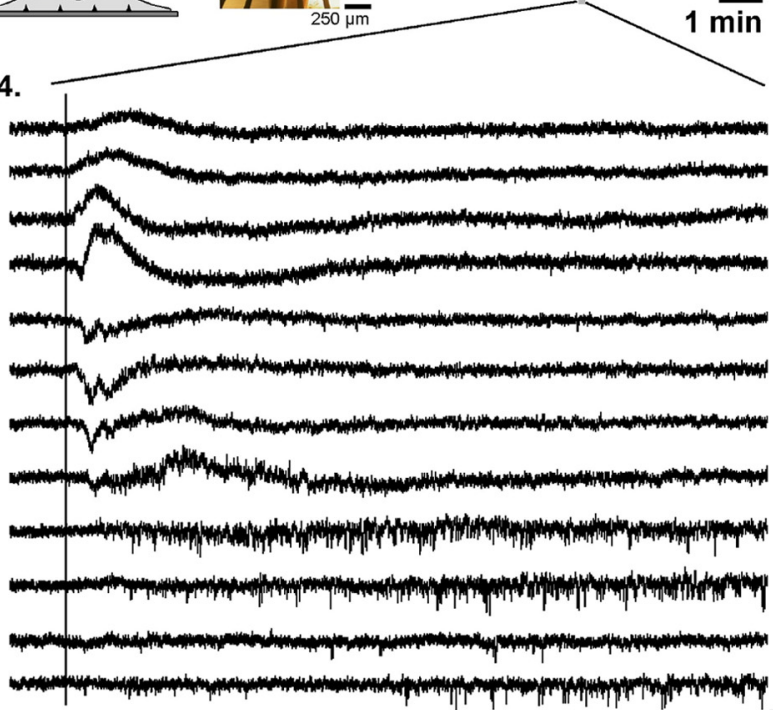

a5.

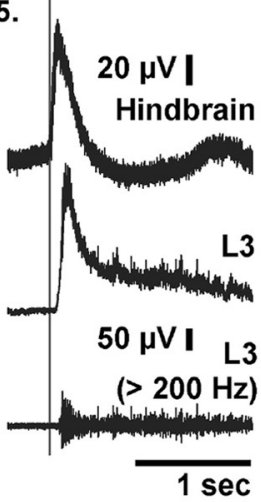

a6.

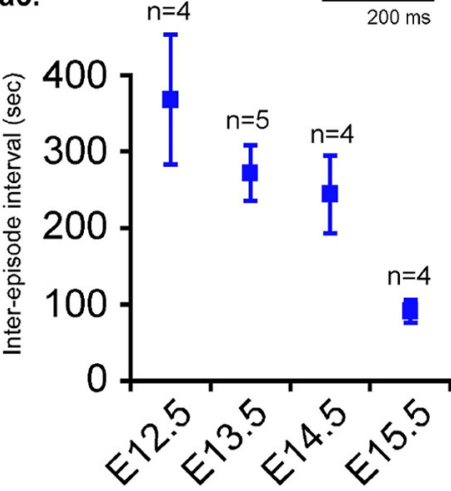

b Cortex

b1.

b2.

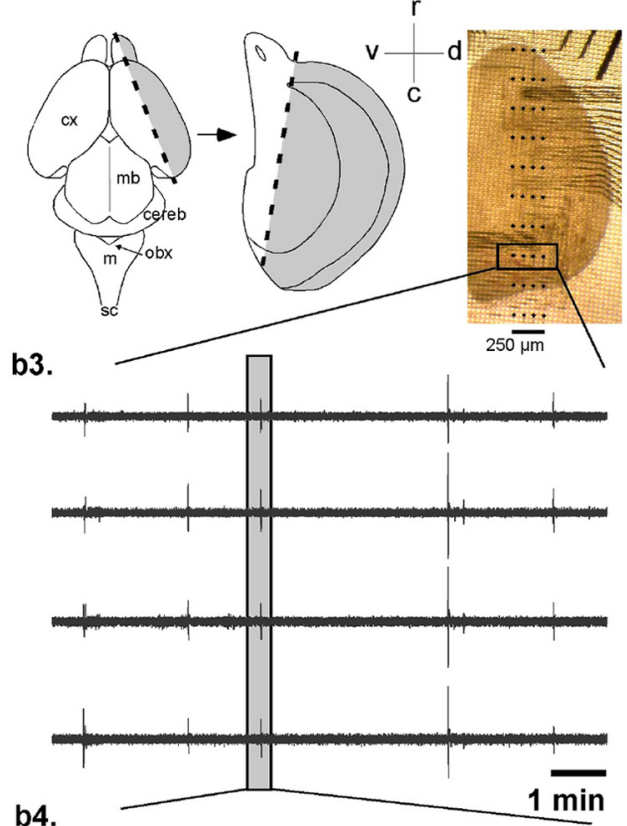

LFPs $(<50 \mathrm{~Hz})$

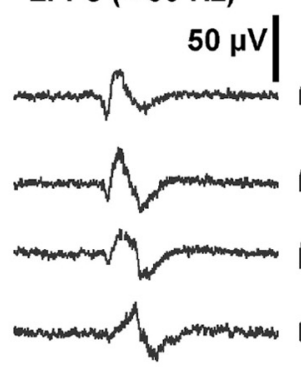

b5.
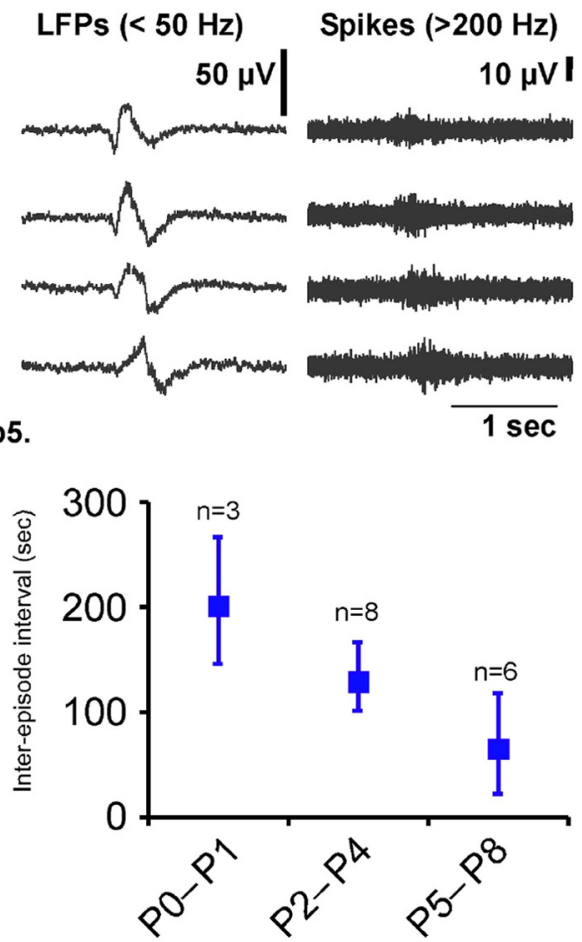

Figure 1. Rhythmicactivityin mouse embryonichindbrain-spinal cord and postnatal cortex. $\boldsymbol{a}$, Hindbrain-spinal cord activity. $\boldsymbol{a}$, Schematicrepresentation ofthewholemouseembryonic CNS. The hindbrain and spinal cord preparations wereisolated from themorecaudal part of the CNS (gray zone), opened dorsallyalong theneural tube (central panel), and positioned on MEAs (bottom panel) so that theependymal surface offourth ventricle and central canal was exposed to aCSF flow. a2, Microscope photography of a wholeE14.5 hindbrain-spinal cord preparation on a $15 \times 4$-channel MEA. The interelectrode distance was $750 \mu \mathrm{m}$ rostrocaudally and $250 \mu \mathrm{m}$ mediolaterally. a3, a4, Example of raw unfiltered data from 12 electrodes of the array (circled in a2) showing four episodes of rhythmic activity, one of which is detailed in a4 to show the rostrocaudal propagation from the hindbrain to the spinal cord. Note thatall traces in $\mathbf{a} 4$ are unfiltered:LFPs aremore ample in the hindbrain, while bursts of spikes are preponderant in the spinal cord. $\mathbf{a 5}$, Simultaneous recordings of hindbrain and $\mathbf{L} 3$ ventral root on anE14.5 preparation (top 2tracesrawsignals, third tracehigh-passfitered) revealed therostrocaudal delay (seevertical bar) between the onset of thehindbrain LFPand theonset of theventral rootactivity displaying a burst of spikes superimposed on a LFP. Each hindbrain episode triggered a local field potential and a burst of spikes on lumbar motoneurons ( $n=11$ preparations from E12.5 to E15.5).. a6, The period of the rhythm, which has been quantified on 17 preparations, decreased during the course of development (linear regression $p=0.002$ and Kruskal-Wallis test across all five stages E12.5 to E15.5: $p=0.02) . \boldsymbol{b}$, Cortical activity. $\boldsymbol{b} 1$, $\boldsymbol{b} 2$, Schematic representation of the forebrain of a newbom mousepup ( $\boldsymbol{b} 1$, leftpanel), from which a part of cortex was isolated ( $\boldsymbol{b} 1$, gray zone in right panel) and then positioned on MEAs ( $\boldsymbol{b} 2$ ), with aCSF flowing overthe innerventricle wall. b3, Rhythmic activity was expressed in a restricted area of the preparation corresponding to the entorhinal cortex. $\mathbf{b 4}$, Each episode, characterized by LFPs (left, low-pass filtered data) on which bursts of spikes were superimposed (right, high-pass filtered data), propagated over this region. $\mathbf{6 5}$, The period of the cortical rhythm, quantified on 17 preparations, decreased during the course of development (linear regression $p<0.02$ and Kruskal-Wallis test across the three stage groups P0-P1,P2-P4, and P5-P8: $p<0.07$ ). cc, Central canal; cereb, cerebellum; $c x$, cortex; $m$, medulla; $m b$, midbrain; obx, obex; $p$, pons; sc, spinal cord; r, rostral; c, caudal; v, ventral; d, dorsal. 
spinal cord preparation was isolated. The day following the mating night was defined as E0.5. The neural tube was opened dorsally and meninges were removed before positioning on microelectrode arrays (MEAs). The cortical preparations were dissected from newborn pups killed by decapitation and meninges were also removed. In both cases, the tissue was dissected in aCSF solution gassed with carbogen $\left(95 \% \mathrm{O}_{2}\right.$ and $\left.5 \% \mathrm{CO}_{2}\right)$ and composed of the following (in $\mathrm{mm}$ ): $113 \mathrm{NaCl}, 4.5 \mathrm{KCl}, 2$ $\mathrm{CaCl}_{2} \cdot 2 \mathrm{H}_{2} \mathrm{O}, 1 \mathrm{MgCl}_{2} \cdot 6 \mathrm{H}_{2} \mathrm{O}, 25 \mathrm{NaHCO}_{3}, 1 \mathrm{NaH}_{2} \mathrm{PO}_{4} \cdot \mathrm{H}_{2} \mathrm{O}$, and 11 D-glucose). Unless otherwise stated, the neural tissue was continuously superfused with aCSF at a rate of $1-2 \mathrm{ml} / \mathrm{min}$. The aCSF was either gassed with carbogen (oxygenated case) or not (nonoxygenated case). For MEA recordings, preparations were stabilized by a plastic net with small holes $\left(70 \times 70 \mu \mathrm{m}^{2}\right)$ to achieve a tight and uniform contact with the microelectrodes. Experiments were performed at room temperature to avoid temperature variations when modifying the rate of perfusion.

Recordings and data analysis. MEA recordings used $4 \times 15$-channel MEA chips from Ayanda BioSystems connected to a MEA1060 amplifier from Multi Channel Systems (MCS), with $\times 1200$ gain and $1-3000 \mathrm{~Hz}$ bandpass filters. Conventional extracellular and ventral root recordings were performed using glass pipettes ( $\sim 20 \mu \mathrm{m}$ tip diameter) connected to World Precision Instruments amplifiers, using $\times 1000$ gain and 1-3000 $\mathrm{Hz}$ filter bandwidth. In all cases, acquisition was performed using two 32-channel Power1401 synchronized by an external trigger and controlled by Spike2 v6 from Cambridge Electronic Design (CED). Local field potentials (LFPs) were extracted by low-pass filtering the raw data below $50 \mathrm{~Hz}$. Spike bursts were extracted by bandpass filtering the raw data between 200 and $2000 \mathrm{~Hz}$.

Perfusion. Perfusion of aCSF around the tissue (superfusion) in the open chamber (in contact with ambient air) was controlled with a Gilson Minipuls 3 peristaltic pump (Gilson). The perfusion inlet had a $2 \mathrm{~mm}$ diameter. After perfusion stopped, the first $10 \mathrm{~min}$ were discarded to quantify the frequency of episodes not to take into account the transition period of fading activity. The actual speed of perfusion flow in the vicinity of the perfusion inlet was measured optically using $10 \mu \mathrm{m}$ melamine resin microparticles (Sigma Aldrich) diluted in aCSF and visualized using a Sony XC-HR58 Camera. Images were acquired at a speed of 50 frames/s using a Matrox METEOR2-MC/4 acquisition board and the Matrox Inspector v8.0 software. To determine perfusion flow speed, the speed of individual beads was averaged across six regions within $1 \mathrm{~mm}$ of the inlet for a perfusion rate of $100 \mu \mathrm{l} / \mathrm{min}$.

Oxygen and $p H$ measurements. Bath oxygen concentration was monitored using a C862 oximeter and SZ10T probe from Consort. Calibration was performed using distilled water saturated with oxygen (corresponding to 8.3 $\mathrm{mg} / \mathrm{L}$ oxygen concentration at $1 \mathrm{bar}$ ) and $17 \% \mathrm{Na}_{2} \mathrm{SO}_{3}$ zero oxygen solution. Tissue $\mathrm{pO}_{2}$ was measured using the Unisense oximeter and Ox10 probe (10 $\mu \mathrm{m}$ tip diameter) calibrated using the same procedure. The $\mathrm{pH}$ of the bath was measured using a PH Meter1 system and $\mathrm{pH} 10$ probe from Unisense. Calibration was performed in $\mathrm{pH}=4,7$, and 10 buffer solutions.

Statistical analysis. Statistical analysis included linear regressions as well as nonparametric tests: Kruskal-Wallis test for independent data and Quade test with Conover $2 \times 2$ comparison for paired data. In all diagrams, error bars indicate SEM.

Drugs. Drugs were purchased from Sigma-Aldrich.

\section{Results \\ Hindbrain-spinal cord and cortical rhythms}

Two types of rhythmic activity were recorded in the developing hindbrain and cortex. The main features of these two rhythms were first characterized using electrophysiological approaches. In whole isolated mouse hindbrain-spinal cord preparations, electrical rhythmic activity was monitored using MEAs on a day-byday basis between embryonic stages E12.5 and E15.5 $(n=39$ embryos). In these experiments, the outer surface of the opened neural tube faced the MEA substrate, while the inner ependymal wall was exposed to a constant aCSF flow (Fig. 1a1,a2). Under these experimental conditions, this hindbrain-spinal cord preparation expressed rhythmic activity that originated in the hindbrain at the level of the junction between the medulla and pons.
Each hindbrain episode triggered activity along the entire spinal cord (Fig. 1a3). The activity corresponded in all cases to a traveling rostrocaudal wave (Fig. 1a4). When this wave reached the lumbar level of the spinal cord, it elicited LFPs and bursts of spikes on ventral roots (Fig. $1 a 5)(n=11)$. It should be noted that all hindbrain episodes triggered a burst on ventral roots, but not all ventral root bursts were triggered by a hindbrain episode. When ventral root bursts were not triggered by the hindbrain, they were not superimposed on an ample LFP (see Fig. 3). During the course of development, this hindbrain-spinal cord rhythm showed some ontogenetic change. In particular, the period of the rhythm decreased from $368 \pm 85 \mathrm{~s}$ at E12.5 to $91 \pm 15 \mathrm{~s}$ at E15.5 (Fig. 1a6). Interestingly, similar features of rhythmic activity were observed in the isolated immature cortex of newborn P0-P8 mouse pups $(n=17)$. Indeed, when the lateral part of the cortex lining the lateral ventricle was isolated with its outer surface facing the MEA substrate and electrodes so that the inner wall of the lateral ventricle was exposed to the perfusion flow (Fig. 1b1,b2), this isolated cortex expressed rhythmic activity (Fig. 1b3). This rhythm, composed of bursts of spikes superimposed on LFPs, was continuously expressed in the caudal part of the preparation, corresponding to the entorhinal cortex, and propagated ventrodorsally (Fig. 1b4). As for the hindbrain-spinal cord activity, the period of the cortex rhythm decreased during the course of development from $206 \pm 61$ s at P0-P1 down to $70 \pm 48$ s at P5-P8 (Fig. 1b5).

\section{Hindbrain and cortical rhythms are abolished when perfusion halts}

Although both the hindbrain-spinal cord and cortical rhythms were robust and could be recorded during several hours, their expression was strictly dependent upon the flow of aCSF (Fig. 2). Under a constant flow rate, the hindbrain-spinal cord preparation (Fig. 2a, Flow ON left) as well as the cortical preparation (Fig. 2b, Flow ON left) expressed ongoing rhythmic activity as previously described. However, when the perfusion system was stopped (Fig. 2a,b, Flow OFF), these rhythms disappeared within 3-10 min. It is important to note that the lack of activity was not a transient phenomenon but was observed as long as the perfusion system was turned off (for hindbrain-spinal cord: $39 \pm$ $3 \mathrm{~min}$, range $10-58 \mathrm{~min}, n=18$; for cortex: $33 \pm 4 \mathrm{~min}$, range 15-64 $\min , n=17)$. Interestingly, when the aCSF flow along the surface of the preparations was restarted, rhythmic activity resumed within minutes in both the hindbrain-spinal cord (Fig. $2 a$, Flow ON right) and the cortical preparations (Fig. $2 b$, Flow $\mathrm{ON}$ right). These initial experiments suggested strongly that the expression of the so-called "spontaneous" rhythmic activity was in fact permitted or induced by the flow of the aCSF. However, it should be noted that while the hindbrain activity ceased when perfusion stopped, bursts of spikes not superimposed on an ample LFP were still present on ventral roots (Fig. 3).

\section{Mechanical origin of the rhythms}

All preparations tested were able to reexpress rhythmic activity even when perfusion resumed after a long period without flow (e.g., $1 \mathrm{~h}$ ), suggesting that the tissue was not damaged by halting perfusion. However, this cannot rule out a possible transient tissue alteration occurring during the perfusion stop, which could have been the simplest explanation underlying the disappearance of activity. Indeed, under control perfusion, the aCSF was gassed with carbogen $\left(95 \% \mathrm{O}_{2}\right.$ and $\left.5 \% \mathrm{CO}_{2}\right)$, which ensured good oxygenation and maintenance of constant $\mathrm{pH}$ (7.3). By contrast, when perfusion stopped, the oxygen level in the chamber de- 


\section{a Hindbrain}

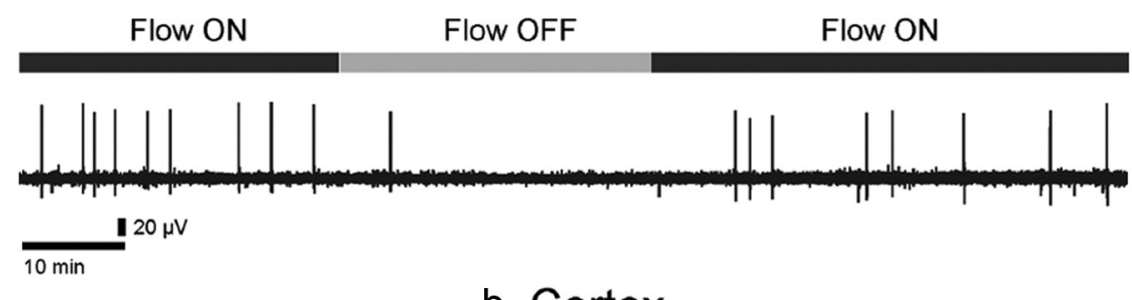

b Cortex

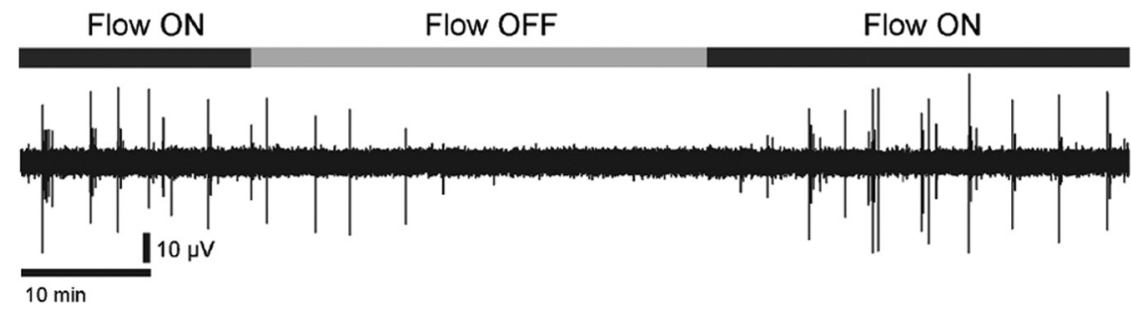

Figure 2. Both hindbrain-spinal cord and cortical rhythms ceased when aCSF flow halted. Rhythmic activity is shown in a for an embryonic hindbrain-spinal cord preparation (E14.5) at the hindbrain level, and in $\boldsymbol{b}$ for a neonatal (P0) cortical preparation. In both cases, ongoing activity (Flow ON) disappeared within a few minutes after aCSF flow halted (Flow OFF) and resumed after flow resumed (Flow $0 \mathrm{~N}$ ).

Flow ON

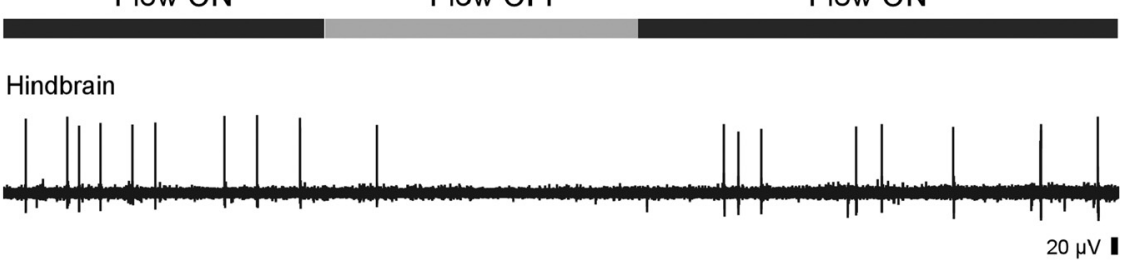

Ventral root L3

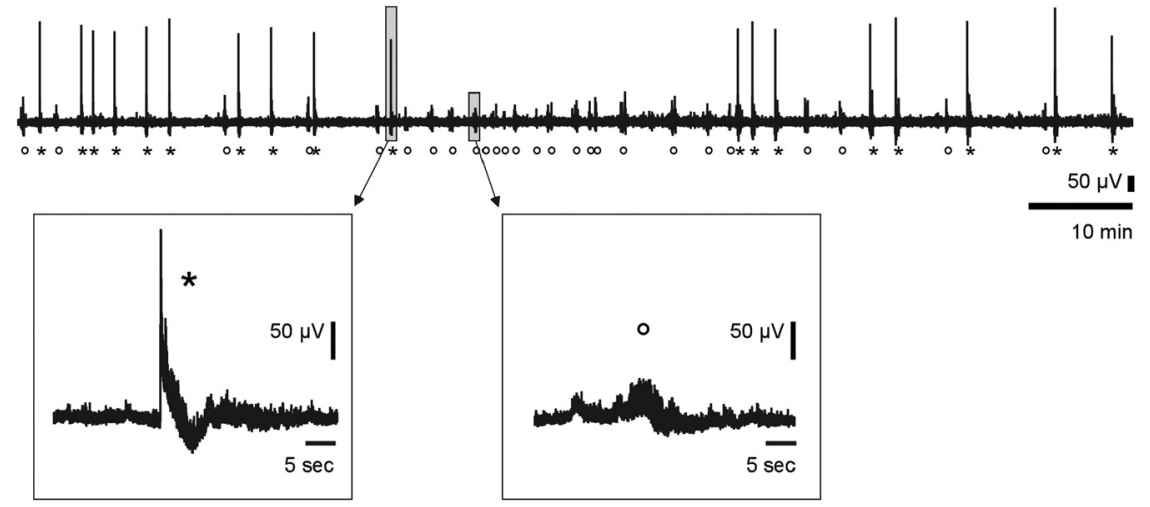

Figure 3. Simultaneous recording of hindbrain and L 3 ventral root during which the perfusion is stopped for $40 \mathrm{~min}$ (E14.5 preparation, same as Fig. 2a). Each hindbrain episode triggers an ample local field potential and a burst of spikes $(*)$ on the ventral root (as in Fig. 1a5). Between these episodes, spontaneous motoneuronal bursts are also observed $(\bigcirc)$ that do not display an ample LFP. When perfusion is stopped, hindbrain activity ceases, while motoneurons still exhibit spontaneous bursting activity ( $)$.

creased and the $\mathrm{pH}$ increased (up to 7.7 within $10 \mathrm{~min}$ ). However, as illustrated in Figure 4, these alterations were not responsible for the disappearance of neural activity. First, performing all experiments at room temperature $\left(22 \pm 3^{\circ} \mathrm{C}\right)$ eliminated the possible effect of temperature changes associated with switching on or off the perfusion flow. Second, both the potential role of a lack of oxygenation and $\mathrm{pH}$ alterations were tested. As illustrated in Figure $4 a$, at all stages between E12.5 and E15.5, the hindbrainspinal cord preparation expressed rhythmic activity under con- trol condition (Flow ON with oxygenated aCSF-95\% $\mathrm{O}_{2}$ and 5\% $\mathrm{CO}_{2}$ - first column), whereas stopping the perfusion abolished the activity (within $343 \pm 73 \mathrm{~s}$, mean \pm SEM) (Flow OFF, second column). Interestingly, however, rhythmic activity resumed (within $245 \pm 67 \mathrm{~s}$ ) when the flow was turned back on with aCSF that was not gassed with carbogen (Flow ON, nonoxygenated aCSF, third column), suggesting that changes in oxygenation or $\mathrm{pH}$ did not account for the disappearance of activity when perfusion halted.

To further confirm this finding, we tested whether it could be the motion itself of the aCSF that was essential for the expression of immature rhythmic activities. For this purpose, after halting the perfusion, we induced a movement of the aCSF in the chamber and monitored oxygen concentration and $\mathrm{pH}$ of the bath. To induce aCSF movement in the chamber, 33-66 $\mu$ l of aCSF was rhythmically flowed in and out at a frequency of $0.5 \mathrm{~Hz}$ and a rate of $\sim 2-4 \mathrm{ml} / \mathrm{min}$ using repetitive back and forth rotations of the pump controlled by computer. We confirmed that the emergence of rhythmic activity depended on liquid movement around the neural tissue (Fig. 4b). Under control condition, with a constant perfusion flow, the preparation expressed rhythmic activity (Fig. 4b, Flow ON, left blue) that was abolished when the flow was stopped (Fig. $4 b$, Flow OFF, middle gray). However, rhythmic activity resumed when the aCSF was rhythmically displaced within the chamber (Fig. $4 b$, right red). As shown in the two lower traces of Figure $4 b$, when perfusion stops, the oxygen level (middle trace) decreases while the $\mathrm{pH}$ (bottom trace) increases (due to the leverage of the acidifying effect of dissolved $\mathrm{CO}_{2}$ ). When aCSF is then displaced in the chamber, the oxygen level remains low and $\mathrm{pH}$ high, while activity resumes. This confirms that changes in oxygenation and $\mathrm{pH}$ in the bath were not responsible for the disappearance of activity in absence of flow. We further confirmed that activity could be recorded for several hours under nonoxygenated $\mathrm{aCSF}$, and that varying the $\mathrm{pH}$ of the bath between 7.2 and 8.2 did not induce the disappearance of activity (Fig. 4c). Finally, we directly tested that hypoxia occurring when the aCSF flow stopped was not responsible for the disappearance of activity (Fig. 5). For this purpose, we directly measured the partial pressure of oxygen $\left(\mathrm{pO}_{2}\right)$ in the hindbrain using a $10 \mu \mathrm{m}$ sensor. Typical $\mathrm{pO}_{2}$ values corresponding to normoxia have been measured to be $\sim 20 \mathrm{mmHg}$ in cortical tissue in vivo (Vovenko, 1999; Sakadzić et al., 2010), a value that has previously been considered to be the threshold for hypoxia (Wilson et al., 2003). Here, the $\mathrm{pO}_{2}$ was $\sim 210 \mathrm{mmHg}$ under an oxygenated aCSF flow rate of 4 
$\mathrm{ml} / \mathrm{min}$, and progressively decreased after aCSF flow stopped (Fig. 5a). However, it clearly appears that activity disappeared well before the tissue became hypoxic. Indeed, as seen in Figure $5 a$, the hypoxia threshold (gray area) was reached several minutes after activity stopped. In particular, no activity was observed for $\mathrm{pO}_{2}$ around $20 \mathrm{mmHg}$, while a normal rhythm was observed at this level of $\mathrm{pO}_{2}$ when nonoxygenated aCSF flowed (Fig. 5b). Thus, hypoxia occurring after the aCSF flow stopped could not account for the disappearance of activity. Altogether, these results indicate that changes in oxygenation, $\mathrm{pH}$ and temperature could not account for the effect of aCSF flow on rhythmic activity.

Moreover, it is important to note that, under displacement of the aCSF, the medium around the tissue was not changed, hence all chemical parameters of the bath remained globally identical to the nomovement situation. This suggests that the presence of the rhythm under normal aCSF flow was unlikely due to the continuous wash of a substance secreted by the tissue that would have accumulated and inhibited activity when perfusion was stopped. To reinforce this idea, we first verified that the disappearance of activity was especially not due to an accumulation of extracellular chloride. Indeed, in immature neural networks where GABA/glycine are excitatory, synaptic events by these neurotransmitters lead to efflux of chloride, which may result in an accumulation of extracellular chloride that could then inhibit activity if not washed by aCSF flow. To eliminate this possibility, we verified that the hindbrain activity was not mediated by an excitatory action of

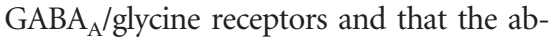
sence of flow still induced the disappearance of activity under blockade of $\mathrm{GABA}_{\mathrm{A}}$ and glycine receptors (Fig. $6 a$ ). In a second step, we also tested whether the disappearance of activity could be due to a local decrease of extracellular potassium concentration $\left[\mathrm{K}^{+}\right]$. As shown in Figure $6 b$, decreasing $\left[\mathrm{K}^{+}\right]$by a factor of $3(1.5 \mathrm{~mm}$ as compared to $4.5 \mathrm{~mm}$ in control condition) did not stop the activity.

Because a chemical effect could still come from the accumulation of another nonidentified substance, we tested whether the position of the perfusion inlet over the preparation influenced the generation of the rhythm. Indeed, if the rhythmic activity depends on the position of the inlet over the preparation while the perfusion rate remains unchanged, it is unlikely that activity change stems from a chemical effect since the overall wash of the bath remains unchanged. We found that this was indeed the case (Fig. 7a). For this experiment, the perfusion inlet $(\sim 500 \mu \mathrm{m}$ in diameter $)$ pointed vertically on the hindbrain at different rostrocaudal positions over the midline. In all cases, the flow rate was 2 $\mathrm{ml} / \mathrm{min}$ and the perfusion outlet was positioned at the caudal

$25 \mu \mathrm{V}$

C
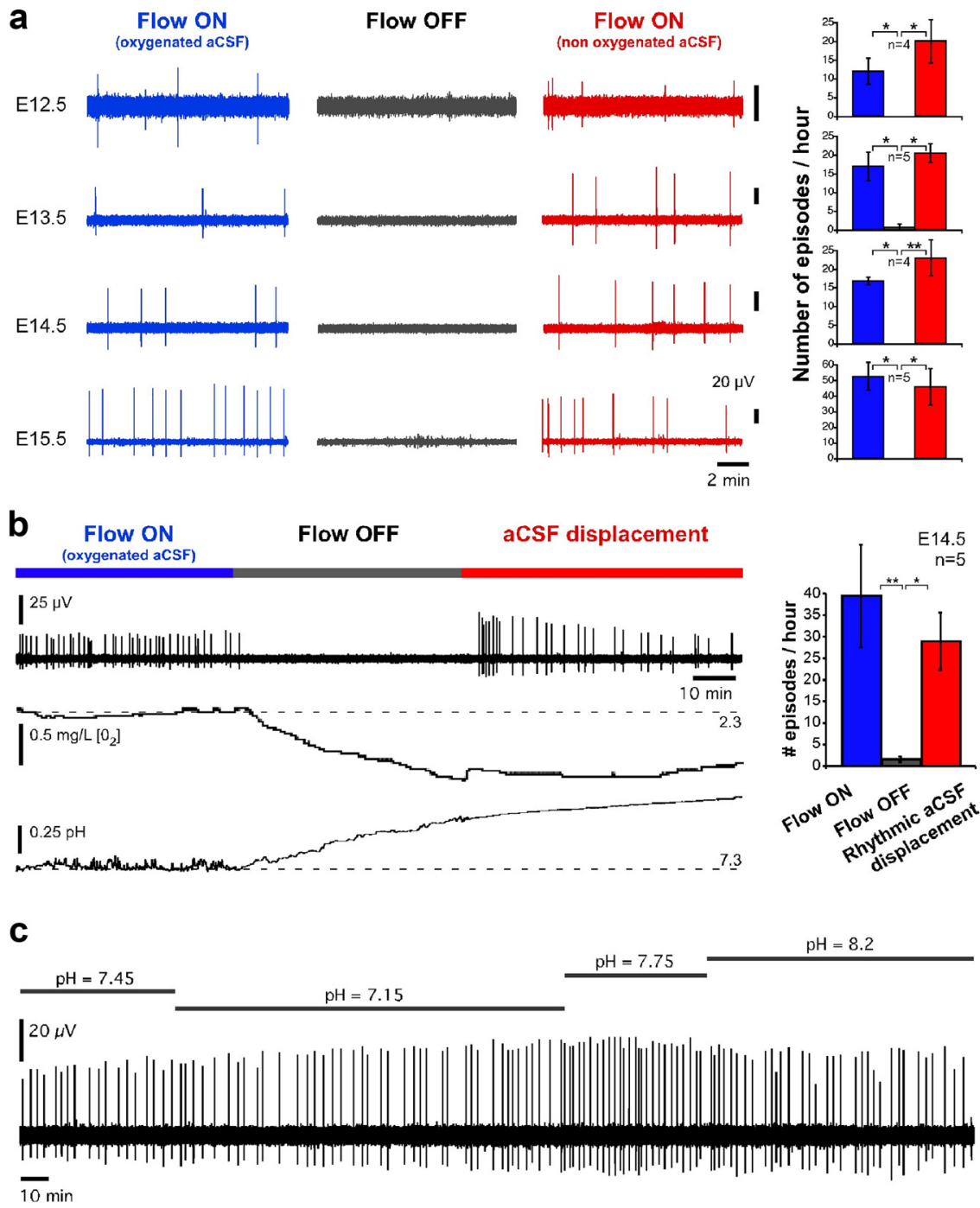

Figure 4. The effect of aCSF flow on the expression of hindbrain rhythmic activity is not due to variations of oxygenation or $\mathrm{pH}$ of the bath. $\boldsymbol{a}$, At all stages of development between E12.5 and E15.5, rhythmic hindbrain-spinal cord activity ceased when perfusion was turned off, and resumed up to control level when nongassed aCSF flow was resumed. $\boldsymbol{b}$, This was of aCSF in and out through the perfusion inlet. Left, Example of such a recording (upper trace) during which bath oxygen concentration (middle trace) and pH (lower trace) were monitored simultaneously. When perfusion stops, oxygenation remains high, but activity resumes. Right, Quantification of the level of activity between the three conditions across five pations. c, Six-hour recording of hindbrain activity under nonoxygenated aCSF with different values of pH. Nonparametric Quade test with Conover 2-by-2 comparison: ${ }^{*} p<0.05,{ }^{* *} p<0.01$, ${ }^{* * *} p<0.001$. Blue, aCSF gassed with carbogen; red, not gassed or displaced aCSF.

end of the preparation. As shown in Figure $7 a$, the activity rate was the fastest when the perfusion inlet was positioned over the hindbrain, and dropped drastically when the inlet was moved rostrally or caudally. Hence, the position of the perfusion was important for the emergence of rhythmic activity, which favors a mechanical action of the aCSF flow. To reinforce again this idea, we finally checked that a mechanical "poke" of the hindbrain (at the junction between medulla and pons) using a glass pipette of $30 \mu \mathrm{m}$ in diameter indeed triggered a wave of activity propagating down the whole preparation (Fig. $7 b$ ).

Overall, these results suggest that the flow of aCSF itself drove the expression of rhythmic activity through a mechanical action on the tissue. 
a

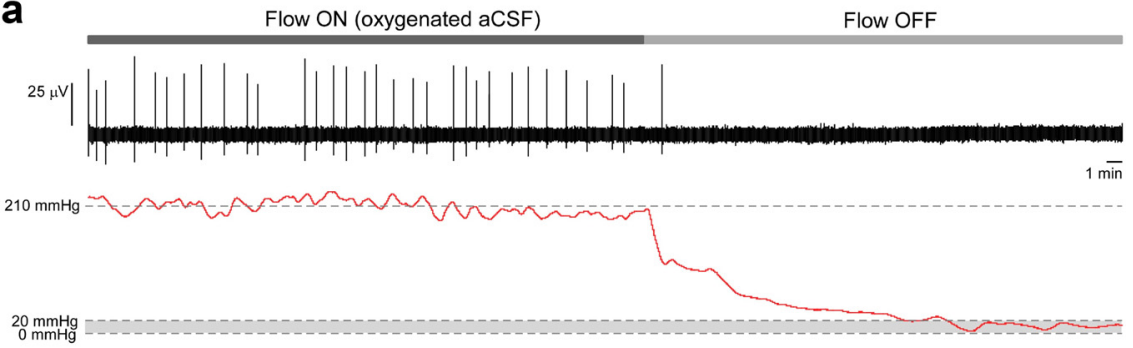

b

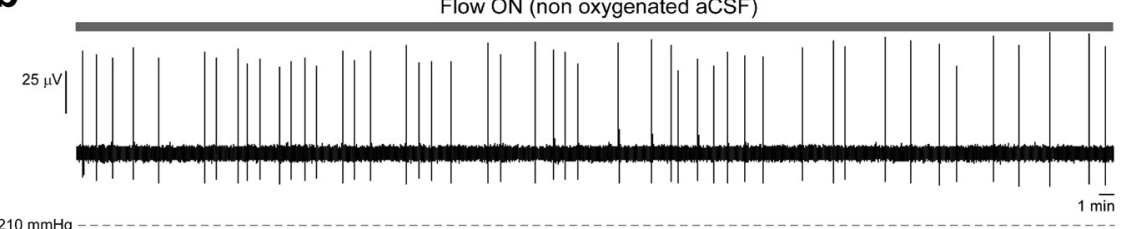

$210 \mathrm{mmHg}$

$20 \mathrm{mmHg}$
$0 \mathrm{mmHg}$

Figure 5. Direct measurement of $\mathrm{pO}_{2}$ in an $\mathrm{E} 14.5$ hindbrain during normal oxygenated aCSF and when perfusion stops $(\boldsymbol{a})$ and under nonoxygenated aCSF flow $(\boldsymbol{b})$. $\boldsymbol{a}$, When the flow of oxygenated aCSF stops, the tissue $\mathrm{p}_{2}$ decreases progressively, but the activity stops before the preparation becomes hypoxic (gray area). In particular, no activity occurs for $\mathrm{p}_{2}$ around $20 \mathrm{mmHg} . \boldsymbol{b}$, By contrast, under flow of nonoxygenated aCSF, rhythmic activity is present for the same level of $\mathrm{p}_{2}$. These data indicate that hypoxia is not responsible for the disappearance of rhythmic activity when aCSF flow stops. In this recording, the flow rate was $4 \mathrm{ml} / \mathrm{min}$ and the sensor tip was positioned as deep as possible in the tissue, just over the floor of the MEA substrate.

\section{a} $150 \mu \mathrm{V}$ Strychnine $(5 \mu \mathrm{M})+$ Bicuculline $(5 \mu \mathrm{M})$

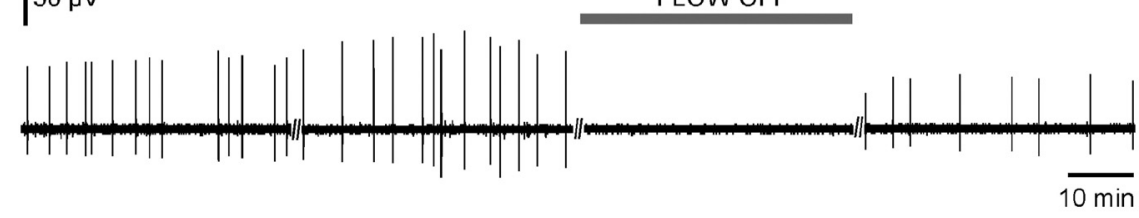

b

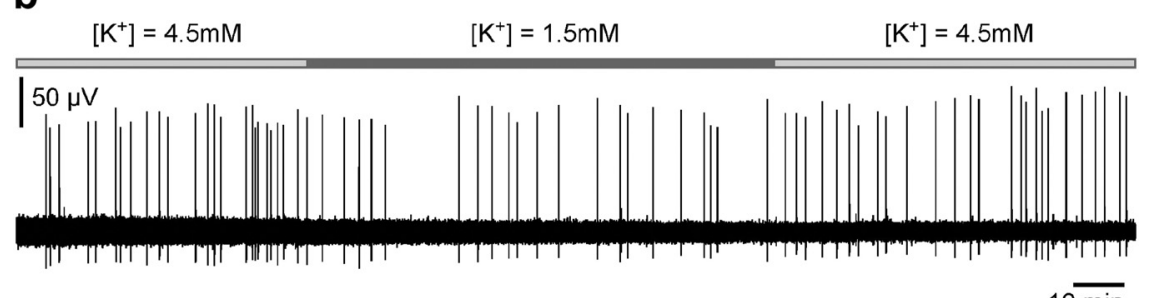

Figure 6. $\boldsymbol{a}$, Hindbrain activity persisted under blockade of $\mathrm{GABA}_{\mathrm{A}}$ and glycine receptors. Moreover, under such blockade, the effect of the flow was still observed. $\boldsymbol{b}$, Activity also persisted under low extracellular potassium concentration.

\section{Perfusion rate determines rhythm frequency}

To further assess the flow-dependent action of aCSF on the expression of activity, the influence of the rate of perfusion on the rhythm frequency was tested (Fig. 7c). For this purpose, the hindbrain-spinal cord preparation was initially perfused at $\sim 1 \mathrm{ml} /$ min and the rate was progressively decreased step by step until no activity was recorded. Each step lasted 25 min during which the rate was maintained constant. The number of hindbrain episodes was quantified during $20 \mathrm{~min}$ after a $5 \mathrm{~min}$ transition period. When activity was no longer observed, the perfusion rate was increased in 25 min steps again. As illustrated in Figure $7 c$, decreasing the speed of aCSF flow from $1 \mathrm{ml} / \mathrm{min}$ to $1 \mu \mathrm{l} / \mathrm{min}$ led to a gradual reduction of the frequency until eventually rhythmic activity vanished (Fig. $7 c$, closed symbols and arrow). Subsequently increasing the perfusion rate led to reestablishing rhythmicity (with some hysteresis), usually with an increase in the rhythm frequency (Fig. $7 c$, open symbols and arrow). It must be noted that when decreasing the speed of perfusion, the characteristic aCSF rate corresponding to half of the maximum rhythm frequency was $\sim 100 \mu \mathrm{l} / \mathrm{min}$ (Fig. $7 c$, asterisk). The speed of aCSF within a distance of $1 \mathrm{~mm}$ from the inlet corresponding to this rate of $100 \mu \mathrm{l} / \mathrm{min}$ was measured optically using $10 \mu \mathrm{m}$ microparticles and found to be of $\sim 22 \mu \mathrm{m} / \mathrm{s}$ (see Materials and Methods). Importantly, this value was comparable to the speed of ventricular ependymal CSF flow in the adult mouse reported to be of the order of 20-30 $\mu \mathrm{m} / \mathrm{s}$ (Ibañez-Tallon et al., 2004; Banizs et al., 2005).

Rhythmic activity occurs when any side of the CNS surface is exposed to flow Because CSF is known to circulate along both the inside and the outside surface of the CNS in vivo, we checked whether the stimulation of the external surface of the neural tube by the aCSF flow could also induce the expression of immature rhythmic activity. For this purpose the hindbrain-spinal cord preparation was flipped so that the aCSF flowed over its outer surface (Fig. $7 d$ ). Under this experimental condition, rhythmic activity similar to that previously observed was expressed under continuous flow, and this activity was also suppressed when the flow was halted and resumed when the flow was turned back on (Fig. $7 d$ ). This observation thus confirms that the aCSF flow acts on either side of the neural tube surface and not only on its inner ependymal side.

Together, these results suggest that the aCSF exerts a mechanical action that in turn controls the expression of rhythmic activity in the immature CNS. Interestingly, the same phenomenon was also observed in the cortical preparation. As illustrated in Figure $8 a$, the cortical rhythm strongly slowed down or even vanished completely when perfusion halted, whereas activity resumed up to control level when a flow of nongassed aCSF was applied. Moreover, the same phenomenon was observed when the outer instead of the inner surface of the cortex was exposed to aCSF flow (Fig. $8 b$ ). For this purpose, the external surface of the whole hemisphere was exposed to flow and recorded using extracellular glass pipettes positioned on the surface of the entorhinal cortex ( $n=8$ additional preparations). In this configuration, rhythmic activity was again strongly reduced or suppressed when perfusion stopped, and resumed when nonoxygenated aCSF was perfused back on. This flow-mediated phe- 
a
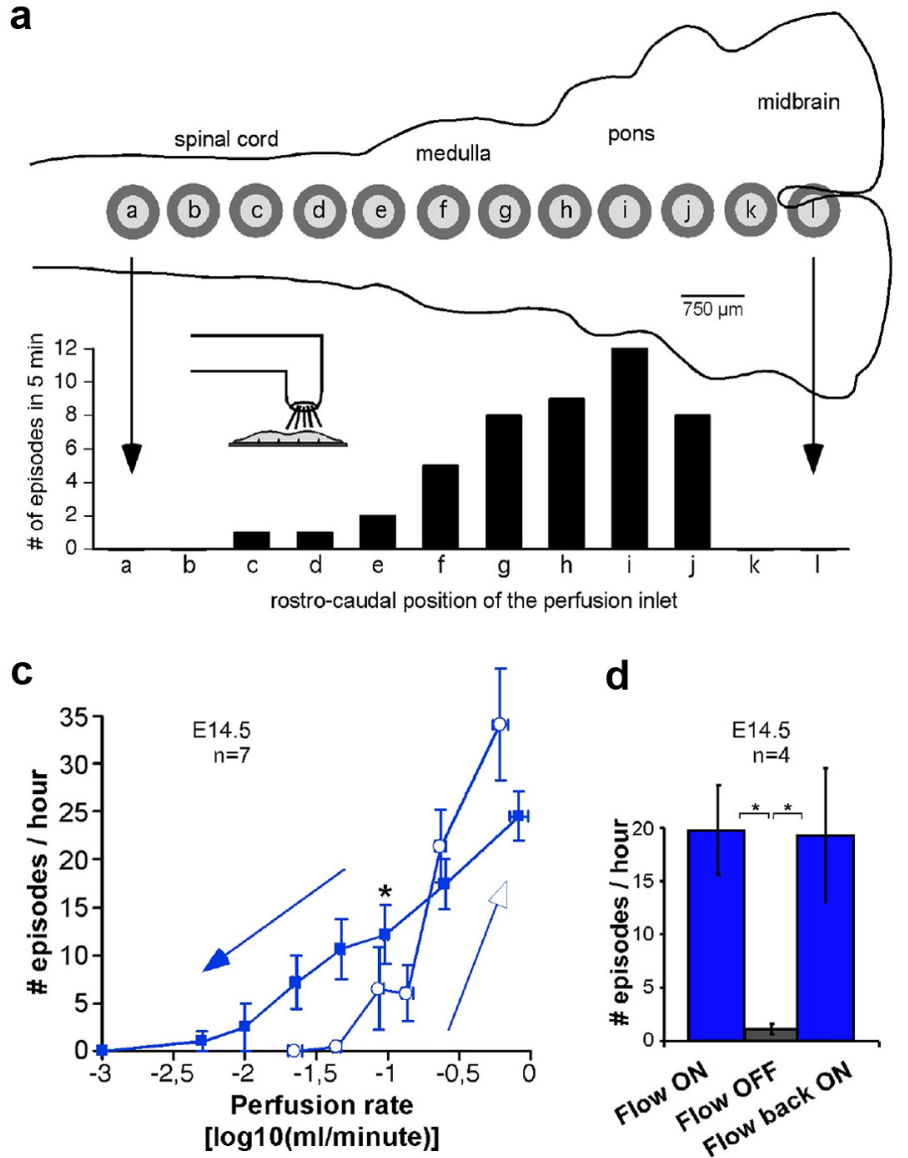

d

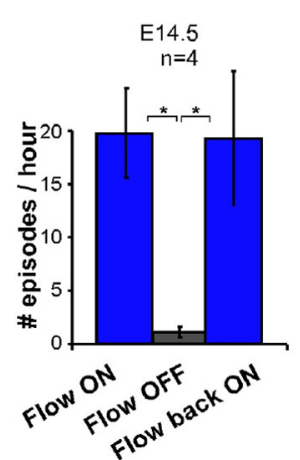

b

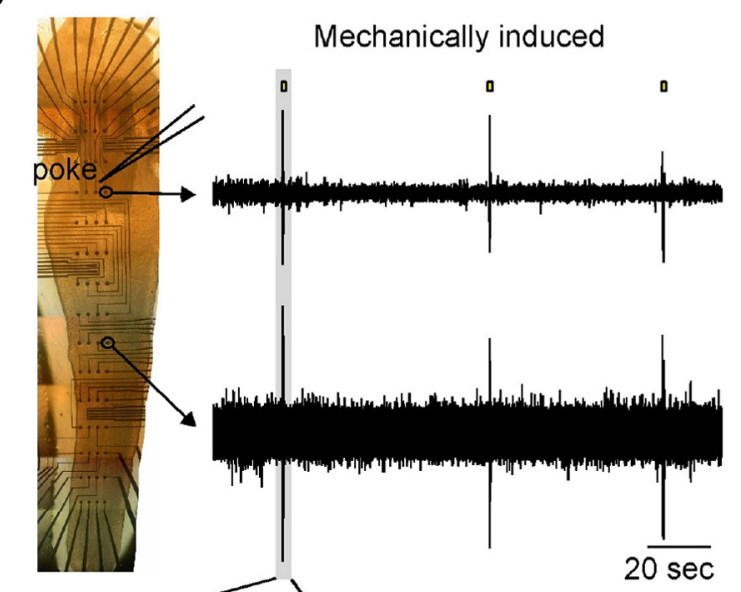

Figure 7. $\boldsymbol{a}$, When the perfusion inlet is oriented directly over the preparation, the frequency of the rhythm strongly depends on its position along the rostrocaudal axis. Here 12 positions along the midline are shown (labeled a-I) and the activity is maximum when the inlet is positioned over the pons and, noticeably, quickly drops when moving rostral over the midbrain. $\boldsymbol{b}$, Waves of activity could also be elicited by a mechanical "poke" of the preparation in the hindbrain. Three such episodes are shown in the top traces for two electrodes of the array (top hindbrain LFP, bottom cervical spikes). As shown below in the close-up view, these mechanically induced episodes resembled closely those induced by the flow of perfusion. $c$, The frequency of the hindbrain rhythm was directly related to the rate of perfusion, with activities seen for flow rates as low as a few tens of microliters per minute. Closed and open symbols and arrows stand for decreasing and increasing perfusion rates, respectively. About $100 \mu \mathrm{l} / \mathrm{min}$ corresponded to half of the maximum rhythm frequency when progressively decreasing flow rate (asterisk). $\boldsymbol{d}$, The effect of perfusion flow was also observed when the preparation was positioned with the central canal facing the electrodes so that the aCSF flowed over the outer surface of the hindbrain.

nomenon was robust and observed at all postnatal stages tested between P0 and P8 (Fig. 8c). As for the hindbrain-spinal cord preparation, movement of aCSF induced in the chamber also led to a reappearance of cortical activity (Fig. $8 d$ ).

\section{Discussion}

In this paper, we raise a concern about the well accepted "spontaneous" nature of immature activity in the developing CNS. Indeed, we show for the first time that the movement of aCSF itself ensures the presence of rhythmic activity. This result has been observed in the developing hindbrain and cortex. Yet, not all forms of rhythmic neural activity disappeared when perfusion halted. In particular, while hindbrain episodes and associated ventral root LFP activity ceased, spontaneous bursts of spikes remained present on ventral root recordings (Fig. 3). Noticeably, these isolated episodes did not display an ample LFP as when they were triggered by the hindbrain (Fig. 3 , insets). The fact that the flow effect is specific to particular forms of activity suggests that it does not stem from a general suffering of the preparation when the flow is stopped. This is further confirmed by the results of Figure 5, where hypoxia occurs after activity vanished.

Although the underlying mechanism remains unknown, these results show that the aCSF flow ensures the emergence of the rhythms described here. One hypothesis would be that the flow- ing fluid continuously washes accumulating metabolites having an inhibitory action on rhythmic activity and is thus permissive for the emergence of activity. Although we eliminated several possible chemical sources for this phenomenon (Figs. 4-6), and showed a specific dependence of the rhythm frequency upon the location of the perfusion inlet (Fig. 7a), this possibility cannot be fully excluded by the present study. Indeed, displacement of the inlet may induce local changes in the wash within the tissue, while the global wash of the bath remains unchanged.

Alternatively, we propose that the flow may exert a mechanical action on the neural tissue that drives the emergence of rhythmic activity. Although widely described in many body functions and within the CNS [including the spinal cord (Grillner et al., 1981)], mechanotransduction has only quite recently been reported to play a role in development. In particular, extra embryonic fluid flow generated around presomite stage E7.5 on the ventral side of the node by motile cilia was found to determine the establishment of left-right asymmetry of the mouse body (Nonaka et al., 2002). At later stages, fluid sheer stress in the vascular system promotes hematopoietic development (Adamo et al., 2009). In the CNS, it has been shown recently that mechanical action or hypoosmotic stress induces liberation of glycine in the embryonic spinal cord by radial cell progenitors (Scain et al., 

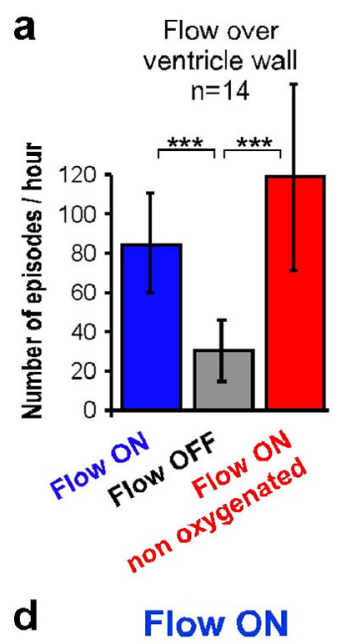
(oxygenated aCSF)

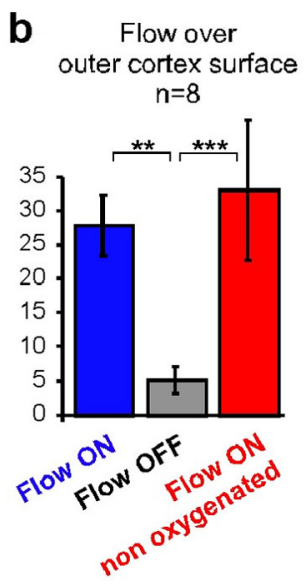

\section{Flow OFF}

C

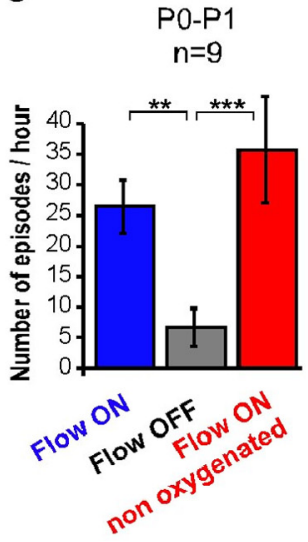

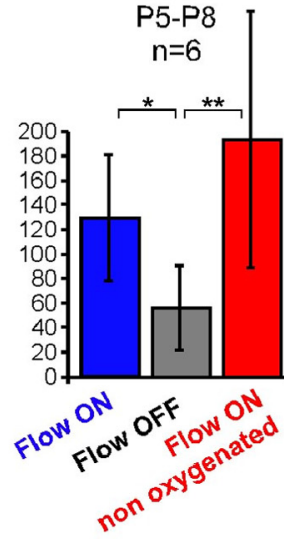

P5-P8

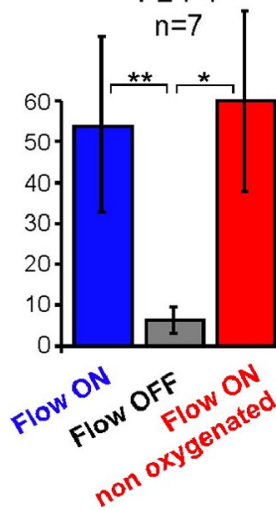

aCSF displacement
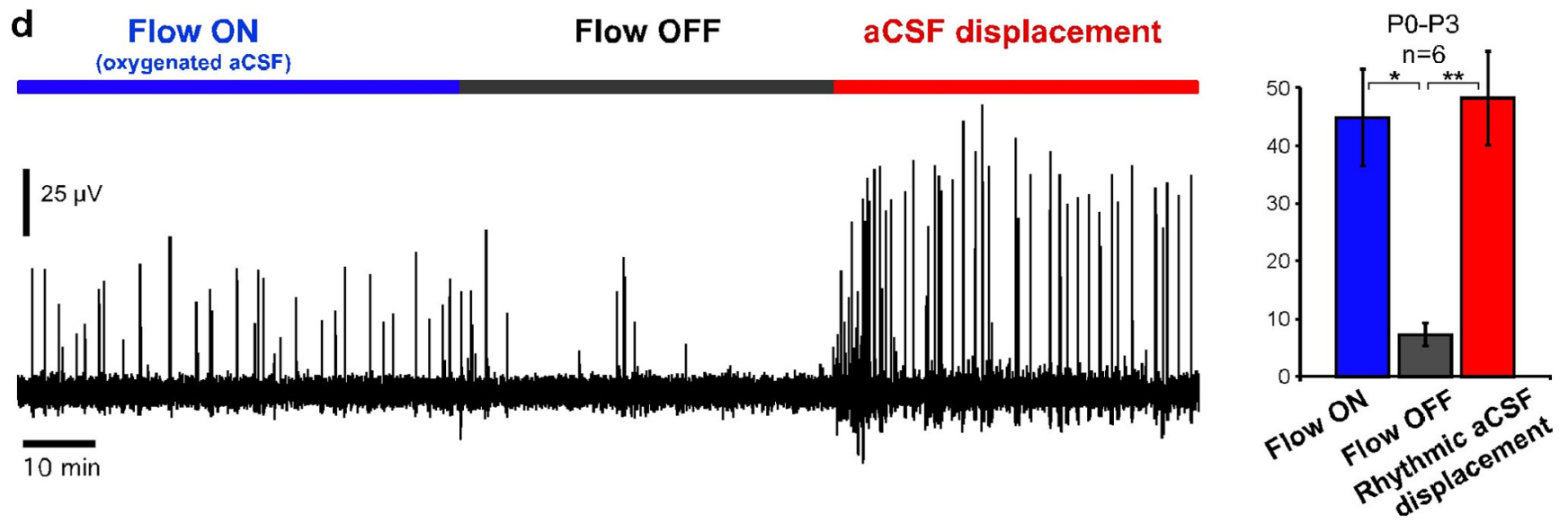

Figure 8. The effect of aCSF flow on the expression of cortical rhythmic activity is not due to variations of oxygenation or pH of the bath. $\boldsymbol{a}$, Rhythmic cortical activity was abolished or strongly reduced when perfusion flow running over the inner ventricular wall halted. Again, this could not be attributed to oxygenation variations since activity resumed to control level when nonoxygenated aCSF flow resumed. $\boldsymbol{b}$, This result was also obtained when aCSF flowed over the outer surface of the cortex. $\boldsymbol{c}$, This effect of perfusion was observed at all developmental stages between P0 and P8. $\boldsymbol{d}$, Rhythmic displacement of aCSF in the chamber restores cortical activity up to a level on average comparable to that observed under normal aCSF perfusion. Nonparametric Quade test with Conover 2-by-2 comparison: ${ }^{*} p<0.05,{ }^{* *} p<0.01,{ }^{* *} p<0.001$. Blue, aCSF gassed with carbogen; red, not gassed or displaced aCSF.

2010). However, the phenomenon observed in the present study seems different since blockade of GABA and glycine receptors did not affect rhythmic activity and its flow dependence (Fig. 6a). Previous structural studies using electron microscopy have pointed out the existence of CSF-contacting neurons (including in the medulla) that extend processes (dendrites and synapses) into the ventricles and may thus sense the flow of CSF (Vígh et al., 2004). A continuous solicitation of these neuron compartments may maintain a sustained excitability of the cells sufficient to activate intrinsic cellular properties known to be involved in rhythmogenesis [e.g., persistent sodium currents (Del Negro et al., 2005)]. Yet, a direct activation of neurons through CSFcontacting processes would be expected to act rapidly, which is not what we observed here. Indeed, in contrast with classical mechanotransduction in the CNS that operates nearly instantaneously (for instance in the cochlea), the effect of aCSF flow observed here is not immediate but rather occurs on the order of minutes (see Figs. 2, $4 b$, and $8 d$ and the hysteresis effect observed in Fig. 7c). This feature suggests that the underlying mechanism might be more complex, possibly entailing intracellular cascade pathways. Flow sensing by kidney cells has been described to involve the primary cilium, the bending of which induces elevation of intracellular calcium within minutes (Praetorius and Spring, 2003). This structure is present at the surface of most mammalian cells, including neurons (Whitfield, 2004), and me- diates different cellular pathways during development (Gerdes et al., 2009). Further works should determine whether such intracellular cascades are at the origin of the action of aCSF flow observed here.

As shown in Figure $7 a$, pointing the perfusion inlet over particular locations of the hindbrain dramatically influenced the rhythm frequency. This result could partly be due to the pressure exerted by the inflow onto the underneath tissue. However, for all other experiments carried in this study, the perfusion inlet was generally located away from the tissue, so that no particular pressure was exerted onto the hindbrain. Thus, the emergence of activity could not generally be attributed to the application of pressure, but rather to the flow of aCSF running over the tissue. It should be noted that in Figure $7 a$, no activity was measured for locations $\mathrm{a}, \mathrm{b}, \mathrm{k}$, and $\mathrm{l}$ only because of the short time of recording at each position (only $5 \mathrm{~min}$ ).

In the present study, the rate of rhythmic activity was determined by the speed of aCSF flow. Interestingly, the typical speed of aCSF that was necessary for the emergence of rhythmic activity was of the order of $20 \mu \mathrm{m} / \mathrm{s}$ (Fig. 7c), which corresponds to the estimated speed of CSF in the adult mouse ventricles due to the beating of motile ependymal cilia. It should be noted, however, that to our knowledge, there are no data yet reporting the speed of CSF in the mouse embryo. Because motile ependymal cilia form only at postnatal stages in the mouse (Spassky et al., 2005), it is 
likely that CSF flows according to other mechanisms than in adults. Further studies should thus address these mechanisms and measure CSF flow in the embryonic ventricles. In particular, further work should determine whether CSF speed in the embryo is comparable to that measured in the adult brain, and thus is compatible with flow rate values found here to be necessary to ensure the presence of rhythmic activity. Moreover, the flowdependent phenomenon, described here ex vivo, also remains to be uncovered in vivo.

In conclusion, the present study suggests that intracerebral CSF movement may act as a primordial mechanical source underlying the generation of rhythmic activity in the developing CNS. Because rhythmic activity is mandatory for the establishment of neural connectivity, this newly described phenomenon may play a central role in the functional maturation of the nervous system.

\section{References}

Adamo L, Naveiras O, Wenzel PL, McKinney-Freeman S, Mack PJ, GraciaSancho J, Suchy-Dicey A, Yoshimoto M, Lensch MW, Yoder MC, GarcíaCardeña G, Daley GQ (2009) Biomechanical forces promote embryonic haematopoiesis. Nature 459:1131-1135.

Allène C, Cattani A, Ackman JB, Bonifazi P, Aniksztejn L, Ben-Ari Y, Cossart R (2008) Sequential generation of two distinct synapse-driven network patterns in developing neocortex. J Neurosci 28:12851-12863.

Banizs B, Pike MM, Millican CL, Ferguson WB, Komlosi P, Sheetz J, Bell PD, Schwiebert EM, Yoder BK (2005) Dysfunctional cilia lead to altered ependyma and choroid plexus function, and result in the formation of hydrocephalus. Development 132:5329-5339.

Ben-Ari Y (2002) Excitatory actions of gaba during development: the nature of the nurture. Nat Rev Neurosci 3:728-739.

Ben-Ari Y, Cherubini E, Corradetti R, Gaiarsa JL (1989) Giant synaptic potentials in immature rat CA3 hippocampal neurones. J Physiol 416:303-325.

Blankenship AG, Feller MB (2010) Mechanisms underlying spontaneous patterned activity in developing neural circuits. Nat Rev Neurosci 11:18-29.

Cang J, Rentería RC, Kaneko M, Liu X, Copenhagen DR, Stryker MP (2005) Development of precise maps in visual cortex requires patterned spontaneous activity in the retina. Neuron 48:797-809.

Del Negro CA, Morgado-Valle C, Hayes JA, Mackay DD, Pace RW, Crowder EA, Feldman JL (2005) Sodium and calcium current-mediated pacemaker neurons and respiratory rhythm generation. J Neurosci 25:446-453.

Dupont E, Hanganu IL, Kilb W, Hirsch S, Luhmann HJ (2006) Rapid developmental switch in the mechanisms driving early cortical columnar networks. Nature 439:79-83.

Galli L, Maffei L (1988) Spontaneous impulse activity of rat retinal ganglion cells in prenatal life. Science 242:90-91.

Garaschuk O, Linn J, Eilers J, Konnerth A (2000) Large-scale oscillatory calcium waves in the immature cortex. Nat Neurosci 3:452-459.

Gerdes JM, Davis EE, Katsanis N (2009) The vertebrate primary cilium in development, homeostasis, and disease. Cell 137:32-45.

Grillner S, McClellan A, Perret C (1981) Entrainment of the spinal pattern generators for swimming by mechano-sensitive elements in the lamprey spinal cord in vitro. Brain Res 217:380-386.

Hanganu IL, Ben-Ari Y, Khazipov R (2006) Retinal waves trigger spindle bursts in the neonatal rat visual cortex. J Neurosci 26:6728-6736.

Hanson MG, Landmesser LT (2003) Characterization of the circuits that generate spontaneous episodes of activity in the early embryonic mouse spinal cord. J Neurosci 23:587-600.

Hanson MG, Landmesser LT (2004) Normal patterns of spontaneous activity are required for correct motor axon guidance and the expression of specific guidance molecules. Neuron 43:687-701.

Hunt PN, McCabe AK, Bosma MM (2005) Midline serotonergic neurones contribute to widespread synchronized activity in embryonic mouse hindbrain. J Physiol 566:807-819.

Ibañez-Tallon I, Pagenstecher A, Fliegauf M, Olbrich H, Kispert A, Ketelsen UP, North A, Heintz N, Omran H (2004) Dysfunction of axonemal dynein heavy chain Mdnah5 inhibits ependymal flow and reveals a novel mechanism for hydrocephalus formation. Hum Mol Genet 13:2133-2141.

Khazipov R, Sirota A, Leinekugel X, Holmes GL, Ben-Ari Y, Buzsáki G (2004) Early motor activity drives spindle bursts in the developing somatosensory cortex. Nature 432:758-761.

Leinekugel X, Khazipov R, Cannon R, Hirase H, Ben-Ari Y, Buzsáki G (2002) Correlated bursts of activity in the neonatal hippocampus in vivo. Science 296:2049-2052.

Momose-Sato Y, Sato K, Kinoshita M (2007) Spontaneous depolarization waves of multiple origins in the embryonic rat CNS. Eur J Neurosci 25:929-944.

Nishimaru H, Iizuka M, Ozaki S, Kudo N (1996) Spontaneous motoneuronal activity mediated by glycine and GABA in the spinal cord of rat fetuses in vitro. J Physiol 497:131-143.

Nonaka S, Shiratori H, Saijoh Y, Hamada H (2002) Determination of leftright patterning of the mouse embryo by artificial nodal flow. Nature 418:96-99.

O'Donovan MJ (1989) Motor activity in the isolated spinal cord of the chick embryo: synaptic drive and firing pattern of single motoneurons. J Neurosci 9:943-958.

O’Donovan MJ (1999) The origin of spontaneous activity in developing networks of the vertebrate nervous system. Curr Opin Neurobiol 9:94-104.

Penn AA, Riquelme PA, Feller MB, Shatz CJ (1998) Competition in retinogeniculate patterning driven by spontaneous activity. Science 279:2108-2112.

Praetorius HA, Spring KR (2003) The renal cell primary cilium functions as a flow sensor. Curr Opin Nephrol Hypertens 12:517-520.

Provine RR, Sharma SC, Sandel TT, Hamburger V (1970) Electrical activity in the spinal cord of the chick embryo, in situ. Proc Natl Acad Sci U S A 65:508-515.

Sakadzić S, Roussakis E, Yaseen MA, Mandeville ET, Srinivasan VJ, Arai K, Ruvinskaya S, Devor A, Lo EH, Vinogradov SA, Boas DA (2010) Twophoton high-resolution measurement of partial pressure of oxygen in cerebral vasculature and tissue. Nat Methods 7:755-759.

Scain AL, Le Corronc H, Allain AE, Muller E, Rigo JM, Meyrand P, Branchereau P, Legendre P (2010) Glycine release from radial cells modulates the spontaneous activity and its propagation during early spinal cord development. J Neurosci 30:390-403.

Spassky N, Merkle FT, Flames N, Tramontin AD, García-Verdugo JM, Alvarez-Buylla A (2005) Adult ependymal cells are postmitotic and are derived from radial glial cells during embryogenesis. J Neurosci 25:10-18.

Spitzer NC (2006) Electrical activity in early neuronal development. Nature 444:707-712.

Tabak J, Senn W, O’Donovan MJ, Rinzel J (2000) Modeling of spontaneous activity in developing spinal cord using activity-dependent depression in an excitatory network. J Neurosci 20:3041-3056.

Thoby-Brisson M, Trinh J-B, Champagnat J, Fortin G (2005) Emergence of the pre-Botzinger respiratory rhythm generator in the mouse embryo. J Neurosci 25:4307-4318.

Vígh B, Manzano e Silva MJ, Frank CL, Vincze C, Czirok SJ, Szabó A, Lukáts A, Szél A (2004) The system of cerebrospinal fluid-contacting neurons. Its supposed role in the nonsynaptic signal transmission of the brain. Histol Histopathol 19:607-628.

Vovenko E (1999) Distribution of oxygen tension on the surface of arterioles, capillaries and venules of brain cortex and in tissue in normoxia: an experimental study on rats. Pflugers Arch 437:617-623.

Whitfield JF (2004) The neuronal primary cilium — an extrasynaptic signaling device. Cell Signal 16:763-767.

Wilson RJ, Chersa T, Whelan PJ (2003) Tissue PO2 and the effects of hypoxia on the generation of locomotor-like activity in the in vitro spinal cord of the neonatal mouse. Neuroscience 117:183-196.

Yuste R, Peinado A, Katz LC (1992) Neuronal domains in developing neocortex. Science 257:665-669.

Yvert B, Branchereau P, Meyrand P (2004) Multiple spontaneous rhythmic activity patterns generated by the embryonic mouse spinal cord occur within a specific developmental time window. J Neurophysiol 91:21012109. 